CARDIOVASCULAR MEDICINE

\title{
Long term outcome after intracoronary $\beta$ radiation therapy
}

\author{
G Sianos, A Hoye, F Saia, W van der Giessen, P Lemos, P J de Feyter, P C Levendag, R van \\ Domburg, P W Serruys
}

Heart 2005;91:942-947. doi: 10.1136/hrt.2004.038026

See end of article for
authors' affiliations
$\ldots \ldots \ldots \ldots \ldots \ldots \ldots . . .$.
Correspondence to:
Dr Georgios Sianos,
Department of
Interventional Cardiology,
Erasmus MC Rotterdam,
Thoraxcentre Bd 404, Dr
Molewaterplein 40, 3015
GD Rotterdam,
Netherlands; g.sianos@
erasmusmc.nl
Accepted
15 September 2004
.......................

\begin{abstract}
Objectives: To determine the long term outcome after intracoronary $\beta$ radiation therapy (IRT). Setting: Tertiary referral centre.

Methods: The rate of major adverse cardiac events (MACE) was retrospectively determined in 301 consecutive patients who were treated with IRT. MACE was defined as death, myocardial infarction, or any reintervention. Long term clinical outcome was obtained from an electronic database of hospital records and from questionnaires to the patients and referring physicians. Long term survival status was assessed by written inquiries to the municipal civil registries.

Results: The mean (SD) follow up was $3.6(1.2)$ years. The cumulative incidence of MACE at six months was $19.1 \%$, at one year $36.4 \%$, and at four years $58.3 \%$. The target lesion revascularisation (TLR) rate at six months was $12.9 \%$, at one year $28.3 \%$, and at four years $50.4 \%$. From multivariate analysis, dose $<18$ Gy was the most significant predictor of TLR. At four years the cumulative incidence of death was $3.8 \%$, of myocardial infarction $13.4 \%$, and of coronary artery bypass surgery $11.3 \%$. Total vessel occlusion was documented in $12.3 \%$ of the patients.

Conclusions: In the long term follow up of patients after IRT, there are increased adverse cardiac events beyond the first six months.
\end{abstract}

: ntracoronary $\beta$ radiation therapy (IRT) has been evaluated as a treatment modality for restenosis prevention. Randomised studies have confirmed its effectiveness for the treatment of in-stent restenosis, both with $\gamma^{1-3}$ and with $\beta$ emitters, ${ }^{4-6}$ but its effectiveness for de novo lesions especially in combination with the use of stents is questionable. ${ }^{7-9}$

The safety and effectiveness of IRT in the long term has yet to be determined. In a porcine model of restenosis of balloon and stent arterial injury followed by IRT, the inhibition of neointimal formation observed at one month was not sustained at six months. Furthermore, this lack of effect on neointimal formation was accompanied by subacute and late thrombosis that led to cardiac death. ${ }^{10}$ Reports on the long term outcome of small randomised studies and registries have raised issues regarding the long term effectiveness of IRT. The angiographic analysis from the SCRIPPS (Scripps coronary radiation to inhibit proliferation post-stenting) trial at three years showed a reduction of the minimum lumen diameter in irradiated patients but not in the placebo group, ${ }^{11}$ with a further increase in target lesion revascularisation (TLR) between 3-5 years in the irradiated patients only. ${ }^{12}$ In addition, an increase in the revascularisation rate between six months and three years was observed only in the irradiated group of the gamma-WRIST (Washington radiation for instent restenosis trial) randomised trial. ${ }^{13}$ In both studies the overall clinical benefit of brachytherapy was maintained in the long term.

We report the long term outcome of patients treated with IRT for de novo and in-stent restenotic lesions in our centre.

\section{METHODS}

\section{Patient population}

Between April 1997 and December 2002, 331 patients received IRT in our institution. In four patients irradiation was not successful (total success rate 99\%). Fifteen patients treated during 2002 with limited follow up were excluded from this analysis. Another 11 patients who were treated with $\gamma$ radiation (GRANITE (gamma radiation to atheromatous neointima using intracoronary therapy in Europe) study) were also excluded. In total 301 patients were analysed for determination of the long term follow up after IRT. Table 1 presents the baseline characteristics of the patients. Table 2 presents procedural characteristics and radiation details. The prescribed dose with the strontium-90/ yttrium-90 source was based on quantitative coronary angiography (at $2 \mathrm{~mm}$ from the centre line of the source axis) and that with the phosphorus-32 source was based on intravascular ultrasound (at a depth of $1 \mathrm{~mm}$ at the vessel wall). Figure 1 presents the number of patients treated with IRT each year.

\section{Follow up}

Baseline clinical and procedural data were entered prospectively into a dedicated database. Long term clinical outcome was obtained from an electronic database of hospital records. The Thoraxcentre is a tertiary cardiology centre serving a group of 14 local hospitals and is the only one with facilities for percutaneous interventions in the region of Rotterdam. As required by the local medical system organisation all baseline procedures were performed in this tertiary facility, as well as the vast majority of reinterventions.

Long term survival status was assessed by written inquiries to the municipal civil registries. Questionnaires were sent to all living patients focusing on the occurrence of major adverse cardiac events (MACE) such as myocardial infarction and repeat intervention (surgical and percutaneous). The referring physician and institutions and the general practitioners were directly approached whenever necessary. Complete follow up was obtained for all patients.

Abbreviations: BENESTENT, Belgian Netherlands stent; BERT, beta energy restenosis trial; $C A B G$, coronary artery bypass grafting; GRANITE, gamma radiation to atheromatous neointima using intracoronary therapy in Europe; IRT, intracoronary $\beta$ radiation therapy; MACE, major adverse cardiac events; SCRIPPS, Scripps coronary radiation to inhibit proliferation post-stenting; TLR, target lesion revascularisation; TVR, target vessel revascularisation; WRIST, Washington radiation for in-stent restenosis trial 
Table 1 Baseline and procedural characteristics

\begin{tabular}{ll}
\hline & Number (\%) \\
\hline Age (years)* & $59(10.2)$ \\
Men & $215(71.4 \%)$ \\
Medical history & $105(34.9 \%)$ \\
Previous MI & $52(17.3 \%)$ \\
Previous CABG & $158(52.5 \%)$ \\
Previous PTCA & \\
Risk factors & $168(55.8 \%)$ \\
Hypercholesterolaemia & $93(30.9 \%)$ \\
Hypertension & $45(15.0 \%)$ \\
Diabetes & $57(18.9 \%)$ \\
Smoking & $51(16.9 \%)$ \\
Family history & $280(93.0)$ \\
Ejection fraction & $16(5.3 \%)$ \\
Normal (>50\%) & $5(1.7 \%)$ \\
Moderate (35-50\%) & \\
Poor (<35\%) & \\
\hline${ }^{*}$ Mean (SD). & \\
CABG, coronary artery bypass grafting; MI, myocardial infarction; \\
PTCA, percutaneous transluminal coronary angioplasty.
\end{tabular}

Table 2 Procedural characteristics and radiation therapy details

\begin{tabular}{|c|c|}
\hline & Number (\%) \\
\hline Patients & 301 \\
\hline Follow up (range) (years) & $3.6(1.2-5.9)$ \\
\hline One vessel treated & $273(90.7 \%)$ \\
\hline Two vessels treated & $28(9.3 \%)$ \\
\hline Total number of vessels & 329 \\
\hline Failed radiation & $4(1.3 \%)$ \\
\hline Second radiation & $4(1.3 \%)$ \\
\hline \multicolumn{2}{|l|}{ Vessel treated } \\
\hline LM & $2(0.6 \%)$ \\
\hline LAD & $120(36.5 \%)$ \\
\hline RCA & 115 (35.0\%) \\
\hline$L C x$ & $73(22.2 \%)$ \\
\hline SVG & $19(5.8 \%)$ \\
\hline \multicolumn{2}{|l|}{ Dual antiplatelet treatment } \\
\hline None & $51(16.9 \%)$ \\
\hline $1-3$ months & $71(23.6 \%)$ \\
\hline 6 months & $142(47.2 \%)$ \\
\hline$>6$ months & $37(12.3 \%)$ \\
\hline Gp llb/Illa inhibitors & $109(36.2 \%)$ \\
\hline \multicolumn{2}{|l|}{ Study } \\
\hline BERT & $30(10.0 \%)$ \\
\hline Beta-Cath trial & $13(4.3 \%)$ \\
\hline BRIDGE & $11(3.7 \%)$ \\
\hline BRIE & $14(4.7 \%)$ \\
\hline Compassionate use & $23(7.6 \%)$ \\
\hline EURO-START 40 & $12(4.0 \%)$ \\
\hline PREVENT & $29(9.6 \%)$ \\
\hline Routine use ${ }^{*}$ & $169(56.1 \%)$ \\
\hline \multicolumn{2}{|l|}{ Source } \\
\hline & 40 (13.3\%) \\
\hline${ }^{90} \mathrm{Sr} /{ }^{90} \mathrm{Y}$ & $261(86.7 \%)$ \\
\hline \multicolumn{2}{|l|}{ Source length (vessels) (mm) } \\
\hline 32p: 27 & $40(12.2 \%)$ \\
\hline${ }^{90} \mathrm{Sr} /{ }^{90} \mathrm{Y}: 30$ & $142(43.2 \%)$ \\
\hline${ }^{90} \mathrm{Sr} / 90 \mathrm{Y}: 40$ & $109(33.1 \%)$ \\
\hline${ }^{90} \mathrm{Sr} / 90 \mathrm{Y}: 60$ & $38(11.6 \%)$ \\
\hline Tandem radiation $\dagger$ & $48(14.6 \%)$ \\
\hline Delayed radiation $\ddagger$ & $7(2.1 \%)$ \\
\hline
\end{tabular}

*138 of these patients were enrolled in the RENO (radiation in Europe with Novoste) study; tstepwise administration; fpatients who had delay between intervention and the administration of brachytherapy. $B E R T$, beta energy restenosis trial; BRIDGE, $\beta$ radiation investigation with direct stenting and Galileo in Europe; BRIE, beta radiation in Europe; Gp, glycoprotein; $L A D$, left anterior descending coronary artery; $L C x$, left circumflex coronary artery; LM, left main coronary artery; PREVENT, proliferation reduction with vascular energy trial; RCA, right coronary artery; START, stents and radiation therapy; SVG, saphenous vein graft.
Up to six months 168 (56\%) patients underwent angiographic control, which was symptomatically driven in almost $25 \%$ of these.

\section{Definitions}

MACE were defined as death, non-fatal myocardial infarction, and repeat revascularisation. TLR was defined as any surgical or percutaneous reintervention because of restenosis within the irradiated segment or the $5 \mathrm{~mm}$ proximal or distal segment (edge restenosis). Target vessel revascularisation (TVR) was defined as any reintervention driven by lesions located in the treated vessel beyond the target lesion limits. Non-TLR-TVR was defined as any reintervention in vessels other than the target vessel. Coronary artery bypass grafting (CABG) was regarded not as a separate event but as a type of reintervention (TLR, TVR, or non-TLR-TVR). The diagnosis of acute myocardial infarction, indiscriminately $\mathrm{Q}$ or non-Q wave, required a rise of creatine kinase to twice the upper limit of normal together with a rise in creatine kinase $\mathrm{MB}$ fraction. If myocardial infarction was diagnosed after a patient was admitted to another hospital, the diagnosis was confirmed through direct contact with the referring physician and based on the same criteria.

Total occlusion was defined as occlusion of the irradiated segment documented by coronary angiography. Subacute thrombosis was defined as angiographically documented total occlusion at $\leqslant 30$ days. Late total occlusion was defined as angiographically documented total occlusion $>30$ days after the intervention. Thrombotic occlusion was defined as an occlusion that resulted in an acute coronary syndrome (myocardial infarction or unstable angina). ${ }^{14}$

For the determination of the length of follow up, the start day was that of the index procedure with IRT between April 1997 and December 2001. The last day for the follow up was 31 March 2003.

The early period was between April 1997 and June 1999 (at the beginning of routine use of IRT with the RENO registry) and late the period was between July 1999 and December 2001 .

\section{Statistical analysis}

Event-free survival was estimated with Kaplan-Meier curves. Among patient subgroups the log rank test was used to compare survival curves. Data are expressed as mean (SD). Continuous variables were compared by Student's $t$ test and categorical variables by $\chi^{2}$ tests. Significance of all tests was defined at the $\mathrm{p}<0.05$ level. The independent association of clinical characteristics with long term mortality, infarction, TLR, and vessel occlusion (the first occurrence of death, myocardial infarction, or TLR) was tested by using the Cox proportional hazard model. Preselected preprocedural and periprocedural variables were age, sex, diabetes, hypertension, hypercholesterolaemia, smoking, unstable angina, prior myocardial infarction, prior CABG, extent of coronary artery disease, left ventricular ejection fraction, indication for percutaneous transluminal coronary angioplasty (de novo or in-stent restenosis), device used (stent or balloon), dose $(<18$ Gy or $\geqslant G y)$, duration of dual antiplatelet medication ( $<6$ months versus $\geqslant 6$ months $)$, source used, and early versus late experience.

\section{RESULTS}

\section{MACE}

The cumulative incidence of MACE at six months was $19.1 \%$, at one year $36.4 \%$, and at four years $58.3 \%$. Figure 2 shows the MACE-free survival curve. Table 3 presents the total MACE count. At four years, the cumulative incidence of MACE was not dependant on the indication (de novo versus in-stent restenosis, $\mathrm{p}=0.8$ ), the device used (balloon versus 


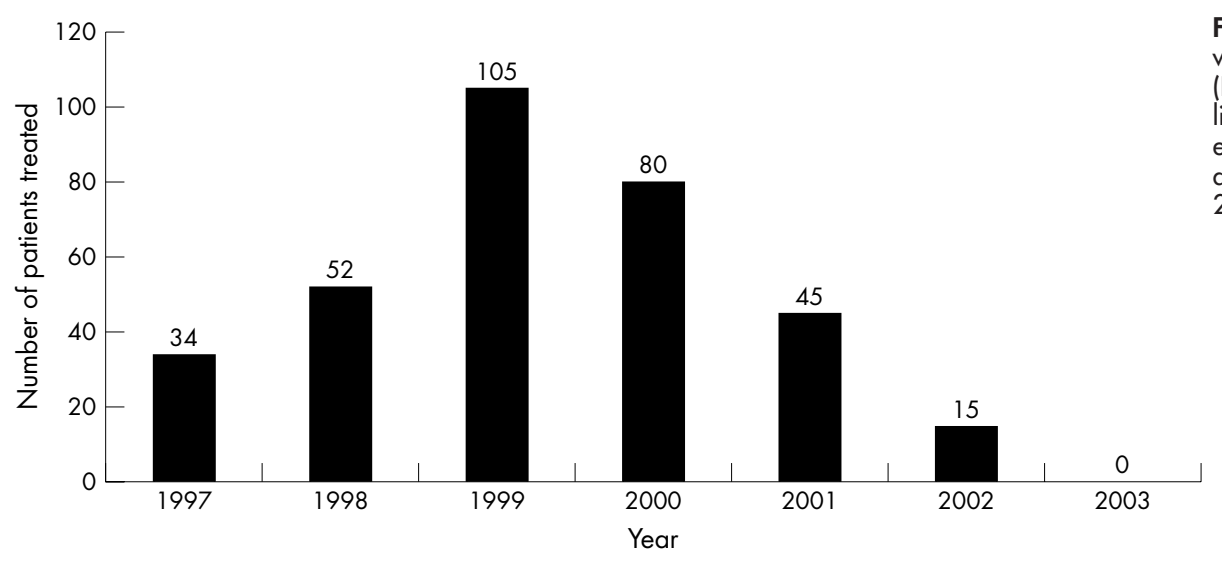

Figure 1 Number of patients treated with intracoronary $\beta$ radiation therapy (IRT) each year. Recognition of the limitations of IRT and the advent of drug eluting stents in the institution dramatically affected the use of IRT after 2000.

stent, $\mathrm{p}=0.5)$, or the early versus the late experience $(p=0.3)$. Table 4 presents the independent predictors of MACE.

At four years the cumulative incidence of death was 3.8\% and of myocardial infarction $13.4 \%$. Half of the deaths were cardiac in origin. A higher incidence of myocardial infarction was observed in patients treated for de novo lesions than in those treated for in-stent restenosis (13.7\% $v 6.3 \%$, $\mathrm{p}=0.04)$.

\section{Reintervention}

The majority $(85 \%)$ of reinterventions were TLRs, with low rates of TVR and non-TLR-TVR observed at four years $(2.3 \%$ and $4.7 \%$, respectively). The cumulative incidence of TLR at six months was $12.9 \%$, at one year $28.3 \%$, and at four years $50.4 \%$. Figure 3 presents the TLR-free survival curve. The mean time to the first TLR was 1.15 (1.0) years. The reintervention-free survival rate at six months was $83.4 \%$ and at four years $46.2 \%$. Table 3 presents the total count of TLR and reintervention. At four years, the cumulative incidence of TLR was dependant on neither the indication (de novo versus in-stent restenosis, $\mathrm{p}=0.8$ ) nor the device used (balloon versus stent, $\mathrm{p}=0.8$ ) (fig 3). TLR was also independent of the period (early versus late, $p=0.4$ ). The cumulative incidence of TLR was higher in patients who received $<18 \mathrm{~Gy}$ than in those who received $\geqslant 18 \mathrm{~Gy}$
Table 3 Total counts of all events

\begin{tabular}{lrrrrr}
\hline & \multicolumn{6}{c}{$\mathbf{6}$ months } & $<\mathbf{1}$ year & $<\mathbf{2}$ years $<\mathbf{3}$ years $<\mathbf{4}$ years \\
\hline Death & 4 & 4 & 9 & 10 & 12 \\
MI & 8 & 17 & 27 & 32 & 32 \\
TLR & 30 & 86 & 119 & 141 & 153 \\
TVR & 5 & 17 & 22 & 23 & 27 \\
Non-TLR or TVR & 15 & 36 & 50 & 58 & 65 \\
Any reintervention & 50 & 139 & 191 & 222 & 245 \\
CABG & 4 & 12 & 22 & 29 & 30 \\
Total occlusions & 6 & 17 & 29 & 34 & 37 \\
\hline
\end{tabular}

All events are reflected-for example, if a patient required repeat intervention and later had an MI the total count would reflect both events and not just the worst one. For CABG and total occlusions the total count of events is the same as the hierarchical ranking, since no patients had these events repeatedly. CABG was not regarded as a separate event but as a type of reintervention.

MACE, major adverse cardiac events; TLR, target lesion

revascularisation; TVR, target vessel revascularisation.

$(\mathrm{p}=0.01)$ (fig 4). Table 4 presents the independent predictors of TLR.

Total occlusions

A total occlusion was documented in 37 patients (12.3\%) (table 3 ). The incidence of subacute thrombosis was $0.3 \%$

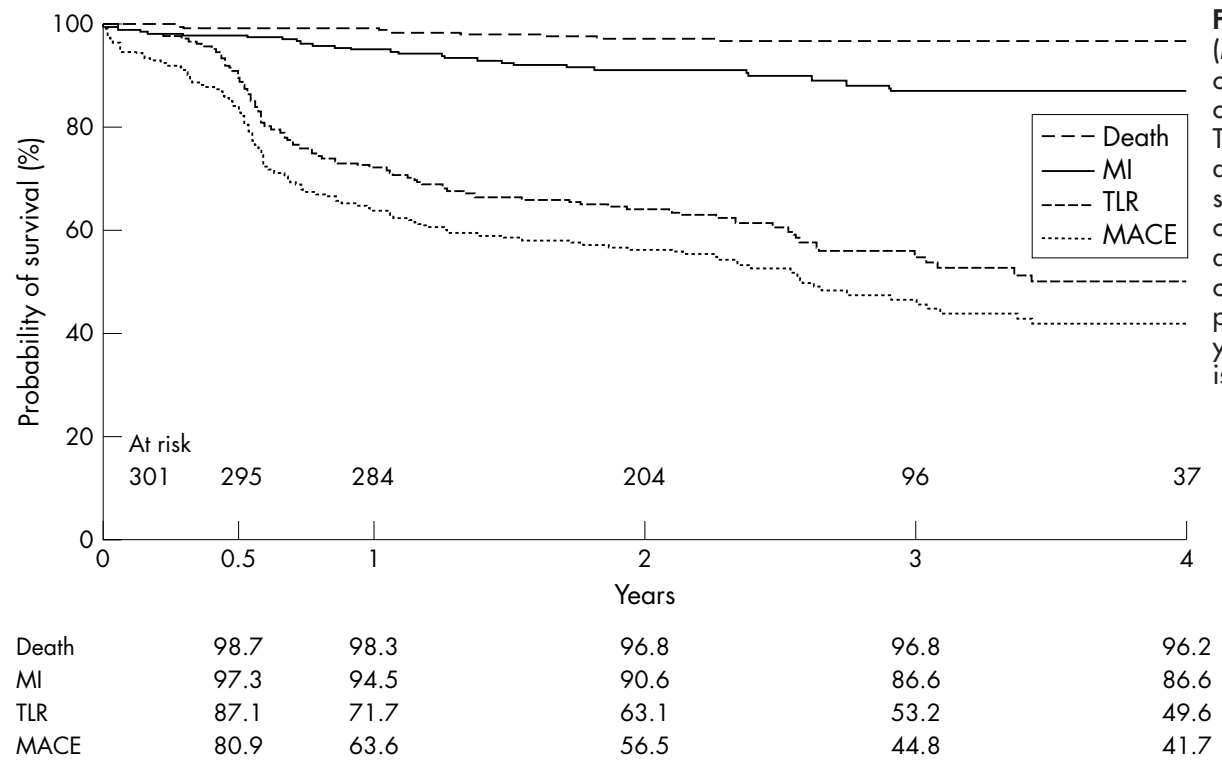

Figure 2 Death, myocardial infarction (MI), reintervention, and major adverse cardiac event (MACE) -free survival curves up to four years (Kaplan-Meier). The target lesion revascularisation (TLR) and MACE curves have three distinct segments. Up to six months a relapse is clearly visible followed by a sharp decrease related to the angiographic control undertaken in almost $56 \%$ of the patients. From one year and up to four years a constant and gradual decrease is clearly visible. 


\begin{tabular}{lll|}
\hline $\begin{array}{l}\text { Table } 4 \text { Independent predictors of MACE and TLR } \\
\text { during follow up }\end{array}$ & \\
\hline & HR & $95 \% \mathrm{Cl}$ \\
\hline MACE & 1.6 & 1.1 to 2.1 \\
Unstable angina & 1.4 & 1 to 2 \\
$\quad$ Hypercholesterolaemia & 1.7 & 1.2 to 2.4 \\
Previous intervention & 1.6 & 1.1 to 2.3 \\
TLR & 1.4 & 1 to 2.1 \\
Dose $<18$ Gy & & \\
Source length $<30 \mathrm{~mm}$ & & \\
\hline Cl, confidence interval; HR, hazard ratio. & & \\
\hline
\end{tabular}

(one of 301) and that of late total occlusion was 12\% (36 of $301)$. Almost half $(6.0 \%)$ were related to an acute coronary syndrome (late thrombotic occlusion). Six patients underwent TLR before the vessel finally occluded. Patients treated for de novo lesions had a higher incidence of total occlusions than did those treated for in-stent restenosis ( $15.4 \% v 7.9 \%$, $p=0.03$ ). The treatment of a de novo lesion was an independent predictor of total vessel occlusion in the long term (hazard ratio $2,95 \%$ confidence interval 1.1 to 5 ).

\section{CABG}

In total 30 patients underwent CABG (table 3). In 15 patients surgery was the first TLR. In 11 patients it was the second TLR, and in one it was the third TLR (recurrence after an initial percutaneous TLR). In two patients CABG was regarded as TVR and in one further patient as non-TLR-TVR.

\section{DISCUSSION}

\section{Evidence of reduced effectiveness over time} Long term outcome for de novo lesions

Very limited data are available for the long term outcome of patients treated with intracoronary radiation for de novo lesions. In the Canadian arm of BERT (beta energy restenosis trial) the TLR rate at six months was $10 \%$ and increased to $23 \%$ at two years indicating a late catch up phenomenon. The positive remodelling observed at six months was lost due to a decrease in minimum lumen diameter between six months and two years. No death, myocardial infarction, or late vessel occlusion was reported in this small cohort of 30 patients. ${ }^{15}$

Long term outcome for in-stent restenosis for $\beta$ and $\gamma$ radiation

In the WRIST series of patients TLR increased by $14 \%$ between six months and two years after both $\beta$ and $\gamma$ radiotherapy, significantly higher than the $2 \%$ increment in the control group. ${ }^{16}$ Between two years and three years TLR increased further by $7 \%$ in patients treated with $\gamma$ radiation therapy compared with $2 \%$ in the control group ${ }^{13}$ indicating that radiation therapy may merely delay the restenotic biological process.

The angiographic analysis from the SCRIPPS randomised study showed a reduction of minimum lumen diameter by $0.37 \mathrm{~mm}$ between six months and three years in the irradiation group; it remained unchanged in the placebo group. ${ }^{11}$ Between six months and five years TLR increased by $11.6 \%$ (from $11.5 \%$ to $23.1 \%$ ) in the irradiated group compared with only $3.5 \%(44.8 \% \vee 48.3 \%)$ in the placebo group; at five years the composite end point of death, myocardial infarction, and TVR no longer reached significance between the two groups. ${ }^{12}$ In both studies, despite the apparent mitigation of efficacy of radiation over time there remained a significant overall benefit in the clinical outcome of irradiated patients compared with the non-irradiated patients in the long term.

In our population between years 1 and 4, TLR increased from $28 \%$ to $50 \%$ and MACE from $36 \%$ to $58 \%$. These results compare poorly with results after conventional stent implantation. In the BENESTENT (Belgian Netherlands stent) I study TLR at five years was $17.2 \%$ ( $2 \%$ increment between years 1 and 5 ) and total MACE was 34.4\% (11\% increment between years 1 and 5). ${ }^{17}$ Even in more complex subsets of patients TLR was not higher than $20 \%$ at up to 10 years' follow up..$^{18} 19$

\section{Indication, dosage administered, and antiplatelet treatment}

There was no difference in the long term outcome based on the indication (de novo versus in-stent restenosis) or the device used (balloon versus stent). Increased dose ( $\geqslant 18 \mathrm{~Gy}$ ) was the strongest radiation related independent predictor of TLR. In patients treated for de novo lesions in a dose finding study the group who received 18 Gy had a better angiographic outcome than the groups receiving lower doses. ${ }^{7}$ In the Long WRIST (WRIST for long lesions) study of patients treated for diffuse in-stent restenosis, improved clinical and angiographic outcomes were observed in the group who received $18 \mathrm{~Gy}$ compared with placebo and those who received $15 \mathrm{~Gy} .{ }^{20}$ Patients treated with $\gamma$ radiation in the Venezuela study had a better long term outcome than did patients from SCRIPPS and WRIST, and the authors speculate that this was related to the higher dose administered during this study. ${ }^{21}$

In the current study the duration of double antiplatelet medication was not a predictor of MACE or TLR. In the WRIST 12 study at 15 months' follow up, patients who received double antiplatelet medication for 12 months had an improved clinical outcome compared with patients who received medication for only six months. ${ }^{22}{ }^{23}$ Since the

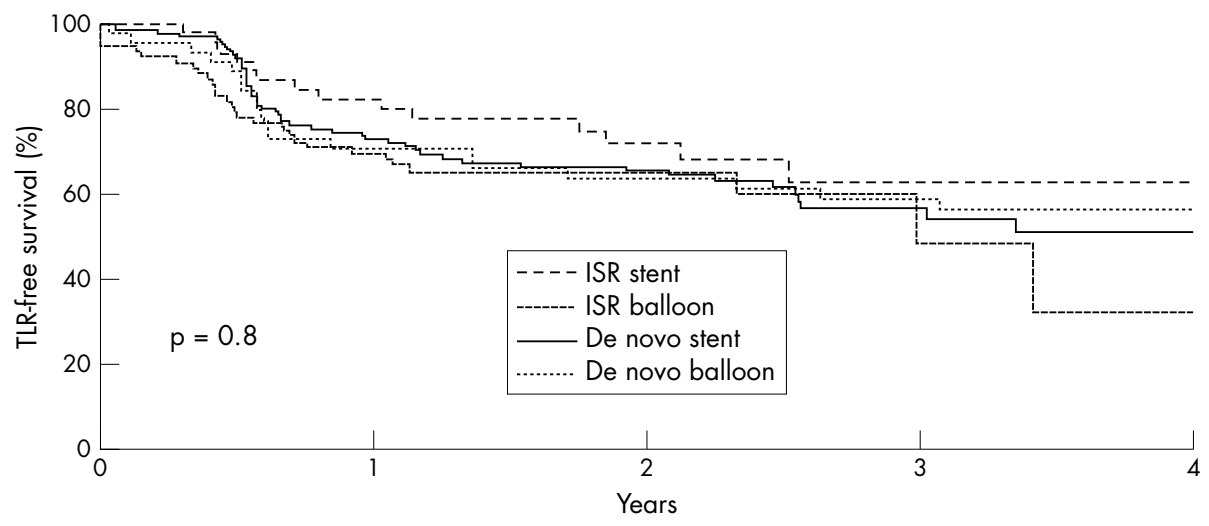

Figure 3 TLR-free survival curves (Kaplan-Meier) based on the indication (de novo/in-stent restenosis (ISR)) and the device used (balloon/stent). 


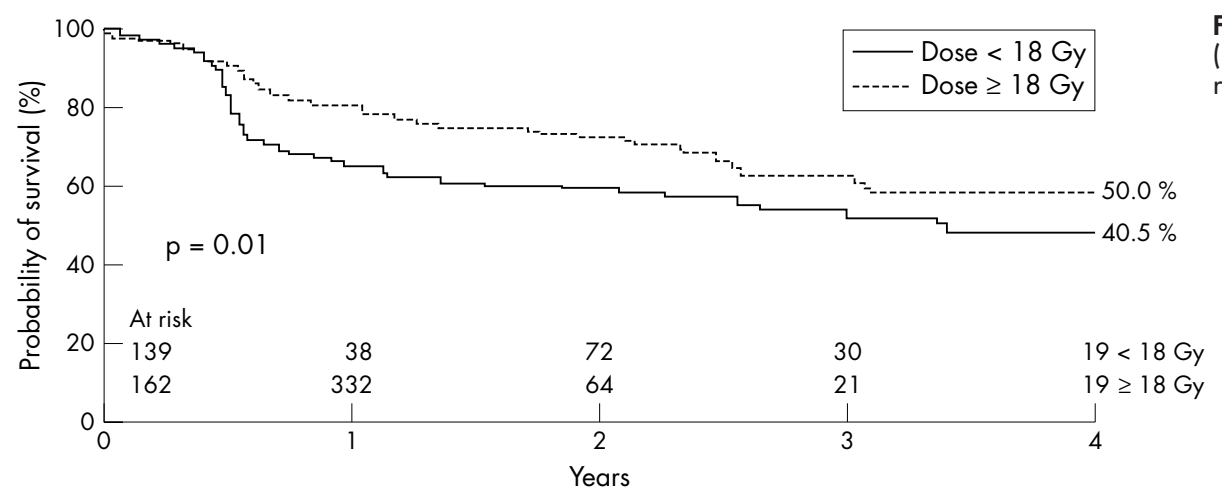

Figure 4 TLR-free survival curves (Kaplan-Meier) for patients who received $<18 \mathrm{~Gy}$ and $\geqslant 18 \mathrm{~Gy}$.

majority of our patients received double antiplatelet medication for six months or less, the duration was probably not long enough.

\section{Total occlusions}

The incidences of late total occlusion and late thrombosis after brachytherapy vary between $6-14 \% .{ }^{14}{ }^{24}$ In our study a $12.3 \%$ incidence of occlusion was documented with the majority of events occurring beyond six months. The real incidence was probably underestimated, as we did not consider silent occlusion in asymptomatic patients without angiographic follow up.

Patients treated for de novo lesions had a significantly higher incidence of total occlusions and myocardial infarction suggesting that brachytherapy should not be used for primary prevention of restenosis.

\section{Brachytherapy in the era of drug eluting stents}

Drug eluting stents have proved to be very effective in preventing restenosis in relatively simple de novo lesions. ${ }^{25}$ Preliminary reports indicate that this beneficial effect is maintained in the long term (up to two years). ${ }^{26}$ These results, in combination with the disappointing outcome of brachytherapy for de novo lesions (especially with the use of stents), have had a dramatic impact on the use of brachytherapy in our centre (fig l).

The broad application of eluting stents may limit brachytherapy as a treatment technique for the limited number of patients with failure of eluting stents.

\section{Limitations}

This is a single centre retrospective analysis with all the limitations originating from such an approach. Patients were enrolled over a period of four and a half years. The dose administered and the duration of dual antiplatelet medication were variable, based on the protocol and the current evidence available at that time.

\section{Conclusions}

In the long term follow up of patients after IRT, adverse cardiac events increase beyond the first six months. IRT delays rather than abolishes cardiac events in the long term. Patients treated with IRT require longer follow up evaluation than those treated with standard techniques.

\section{Authors' affiliations}

G Sianos, A Hoye, F Saia, W van der Giessen, P Lemos, P J de Feyter, P C Levendag, R van Domburg, P W Serruys, Department of Interventional Cardiology, Thoraxcentre, Erasmus MC, Rotterdam, The Netherlands

No financial support was received for this study.

\section{REFERENCES}

1 Teirstein PS, Massullo V, Jani S, et al. Catheter-based radiotherapy to inhibit restenosis after coronary stenting. N Engl J Med 1997;336:1697-703.

2 Waksman R, White RL, Chan RC, et al. Intracoronary gamma-radiation therapy after angioplasty inhibits recurrence in patients with in-stent restenosis. Circulation 2000;101:2165-71.

3 Leon MB, Teirstein PS, Moses JW, et al. Localized intracoronary gammaradiation therapy to inhibit the recurrence of restenosis after stenting. N Engl J Med 2001;344:250-6.

4 Waksman R, Bhargava B, White L, et al. Intracoronary beta-radiation therapy inhibits recurrence of in-stent restenosis. Circulation 2000;101:1895-8.

5 Popma JJ, Suntharalingam M, Lansky AJ, et al. Randomized trial of $90 \mathrm{Sr} / 90 \mathrm{Y}$ beta-radiation versus placebo control for treatment of in-stent restenosis. Circulation 2002;106:1090-6.

6 Waksman R, Raizner AE, Yeung AC, et al. Use of localised intracoronary beta-radiation in treatment of in-stent restenosis: the INHIBIT randomized controlled trial. Lancet 2002;359:551-7.

7 Verin V, Popowski Y, de Bruyne B, et al. Endoluminal beta-radiation therapy for the prevention of coronary restenosis after balloon angioplasty. The DoseFinding Study Group. N Engl J Med 2001;344:243-9.

8 Serruys PW, Sianos G, van der Giessen W, et al. Intracoronary beta-radiation to reduce restenosis after balloon angioplasty and stenting: the beta-radiation in Europe (BRIE) study. Eur Heart $J$ 2002;23:1351-9.

9 Kuntz R, Speiser B, Joyal M, et al. Clinical and angiographic outcomes after use of $\mathrm{Sr}-90$ beta-radiation for the treatment of de novo and restenotic coronary lesions. Congress of the American College of Cardiology, Orlando, March, 2001

10 Kaluza GL, Raizner AE, Mazur W, et al. Long-term effects of intracoronary beta-radiation in balloon- and stent-injured porcine coronary arteries. Circulation 2001;103:2108-13.

11 Teirstein PS, Massullo V, Jani S, et al. Three-year clinical and angiographic follow-up after intracoronary radiation: results of a randomized clinical trial. Circulation 2000; 101:360-5.

12 Grise MA, Massullo V, Jani S, et al. Five-year clinical follow-up after intracoronary radiation: results of a randomized clinical trial. Circulation 2002; 105:2737-40.

13 Ajani AE, Waksman R, Sharma AK, et al. Three-year follow-up after intracoronary gamma radiation therapy for in-stent restenosis: original WRIST. Washington radiation for in-stent restenosis trial. Cardiovasc Radiat Med 2001;2:200-4.

14 Waksman R, Bhargava B, Mintz GS, et al. Late total occlusion after intracoronary brachytherapy for patients with in-stent restenosis. J Am Coll Cardiol 2000;36:65-8.

15 Meerkin D, Joyal M, Tardif JC, et al. Two-year angiographic follow-up of intracoronary Sr90 therapy for restenosis prevention after balloon angioplasty. Circulation 2002;106:539-43.

16 Waksman $\mathbf{R}$, Ajani AE, White RL, et al. Two-year follow-up after beta and gamma intracoronary radiation therapy for patients with diffuse in-stent restenosis. Am J Cardiol 2001;88:425-8.

17 Kiemeneij F, Serruys PW, Macaya C, et al. Continued benefit of coronary stenting versus balloon angioplasty: five-year clinical follow-up of Benestent-I trial. J Am Coll Cardiol 2001;37:1598-603.

18 Kimura T, Abe K, Shizuta S, et al. Long-term clinical and angiographic followup after coronary stent placement in native coronary arteries. Circulation 2002; 105:2986-91.

19 Laham RJ, Carrozza JP, Berger C, et al. Long-term (4- to 6-year) outcome of Palmaz-Schatz stenting: paucity of late clinical stent-related problems. J Am Coll Cardiol 1996;28:820-6.

20 Waksman $\mathbf{R}$, Cheneau $E$, Ajani $A E$, et al. Intracoronary radiation therapy improves the clinical and angiographic outcomes of diffuse in-stent restenotic lesions. results of the Washington radiation for in-stent restenosis trial for long lesions (long WRIST) studies. Circulation 2003;107:1744-9.

21 Condado JA, Waksman R, Saucedo JF, et al. Five-year clinical and angiographic follow-up after intracoronary iridium-192 radiation therapy. Cardiovasc Radiat Med 2002;3:74-81. 
22 Waksman $R$, Ajani $A E$, Pinnow $E$, et al. Twelve versus six months of clopidogrel to reduce major cardiac events in patients undergoing gamma-radiation therapy for in-stent restenosis: Washington radiation for in stent restenosis trial (WRIST) 12 versus WRIST PLUS. Circulation 2002; 106:776-8.

23 Waksman $\mathbf{R}$, Ajani AE, White RL, et al. Prolonged antiplatelet therapy to prevent late thrombosis after intracoronary gamma-radiation in patients with in-stent restenosis: Washington radiation for in-stent restenosis trial plus 6 months of clopidogrel (WRIST PLUS). Circulation 2001;103:2332-5.
24 Costa MA, Sabate M, van der Giessen, et al. Late coronary occlusion after intracoronary brachytherapy. Circulation 1999;100:789-92.

25 Morice MC, Serruys PW, Sousa JE, et al. A randomized comparison of a sirolimus-eluting stent with a standard stent for coronary revascularization. N Engl J Med 2002;346:1773-80.

26 Degertekin M, Serruys PW, Foley DP, et al. Persistent inhibition of neointimal hyperplasia after sirolimus-eluting stent implantation: long-term (up to 2 years) clinical, angiographic, and intravascular ultrasound follow-up. Circulation 2002;106:1610-3.

\section{IMAGES IN CARDIOLOGY}

Anomalous origin of the left coronary artery from the pulmonary artery in an elderly patient visualised by three dimensional multidetector $\mathrm{CT}$ coronary angiography

\begin{abstract}
65 year old woman presented with intermittent atypical substernal discomfort and mild exertional dyspnoea for one year. A transthoracic echocardiogram showed the dilated right coronary artery (RCA) coming from the right coronary cusp of the aorta $(\mathrm{AO})$. Left ventricular function was well preserved without regional wall motion abnormalities.

Subsequent conventional coronary angiography showed the absence of the left coronary artery (LCA) arising from the aorta. Selective right coronary angiography demonstrated an enormously dilated, tortuous and dominant RCA from the right aortic sinus, with profuse collateral channels feeding the left coronary system, and the retrograde left main coronary artery blood flow was later seen emptying into the main pulmonary artery (PA). Multidetector computed tomography (MDCT) coronary angiography was performed by using a 16 channel multidetector row CT scanner (Somatom Sensation 16; Siemens, Forchheim, Germany) with retrospective ECG gating. Scanning parameters were $210 \mathrm{~ms}$ temporal resolution and $16 \times 0.75 \mathrm{~mm}$ detector collimation, and axial images were reconstructed with $1 \mathrm{~mm}$ slice thickness and $0.7 \mathrm{~mm}$ increment. Reconstruction window which was optimal for anomalous coronary artery was chosen at $30 \%$ of the R-R interval. A $110 \mathrm{ml}$ dose of non-ionic iodinated contrast material (Ultravist; Schering, Berlin, Germany) was injected intravenously at $4 \mathrm{ml} / \mathrm{s}$. A $30 \mathrm{ml}$ normal saline bolus was given following contrast material injection to decrease artefact from contrast material in the right heart. The three dimensional reconstruction of the CT coronary angiograph confirmed the anatomic features of the disease demonstrated in the conventional coronary angiography (panels A-D).
\end{abstract}

S-W Rha

H S Yong

C G Park

parkcg@kumc.or.kr
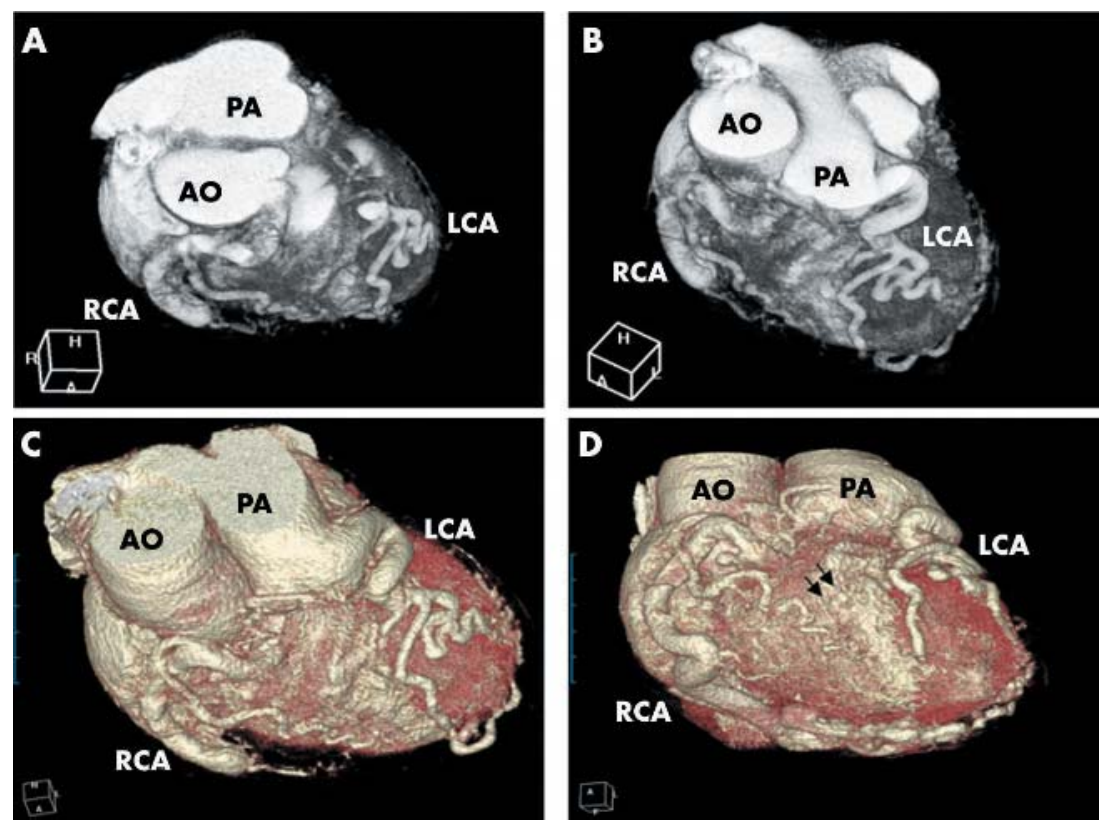

Three dimensional volume rendered view from CT coronary angiography enabled visualisation of dilated right coronary artery (RCA) from the aorta (panel A), anomalous origin of the left coronary artery (LCA) from the pulmonary artery (PA) (panel B), and their anatomical relation with surrounding structures (panel C). Rich collateral channels between the RCA and LCA are shown in panel $\mathrm{D}$ (arrows). $\mathrm{AO}$, aorta. 